\title{
ANALYSIS OF SPEED ON RURAL STATE ROADS - VALLEY ROUTES
}

\author{
Vladan Tubić ${ }^{1}$, Dragana Božić ${ }^{2}$, Nemanja Stepanović ${ }^{3}$ \\ 1,2,3 University of Belgrade, Faculty of Transport and Traffic Engineering, Vojvode Stepe 305, 11000 \\ Belgrade, Serbia
}

Received 15 August 2019; accepted 8 December 2019

\begin{abstract}
Speed, as one of the basic parameters of the traffic flow, has a great importance in terms of efficiency (level of service, travel time) and safety (number of traffic accidents, consequences and risk of accident occurrence). Speed management includes a series of measures that are applied in order to achieve the balance between safety and efficiency in the traffic flow. One of the most important measures for achieving this goal is to define a credible speed limit, i.e. the speed limit that would allow maximization of the capacity and level of service of the observed section, or minimization of users' costs and the risk of traffic accident occurrence. Considering the fact that improper and unadjusted speed causes a number of significant negative effects, the aim of this paper is to carry out the analysis of the credibility of the existing speed limits, i.e. to determine the factors that impact the speed on two-lane sections of valley roads. In order to achieve this, field research in real-world conditions was carried out using the floating vehicle method and an Android phone application. This paper analyzed the speed on the cross-section (time-mean speed). However, it also analyzed the traffic flow speeds on the entire homogeneous impact segment on the basis of automated traffic counters (micro level), as well as on the macro level, i.e. along the six analyzed sections of two-lane rural valley roads (space-mean speed). Also, empirical research determined the speed limit values on the selected sections and free flow speeds on the basis of the Linear Model and by applying the HCS software. Within the speed analysis, the values of operating speeds were determined based on analytical models and methods. In order to obtain a clearer image of the credibility of the existing speed limits, an analysis of the speed limit violations according to classes was carried out.
\end{abstract}

Keywords: speed limit credibility, operating speed, speed management, hourly design volume.

\section{Introduction}

Speed, as one of the basic parameters of the traffic flow, is of great importance in terms of traffic flow efficiency (travel time) and safety (the occurrence and consequences of traffic accidents). Vehicle speed in the traffic flow is a qualitative measure for assessing traffic conditions on the existing and future road network.

Speed limitation is an important measure for achieving the efficient and safe traffic flow. Ideally, the road environment and the speed

${ }^{1}$ Corresponding author: vladan@sf.bg.ac.rs 
limit should be coherent and consistent so that most drivers drive according to the set speed limit. Speed limits represent one of the elements actual conditions, in order to maximize the capacity and level of service of the observed road section, or to minimize the costs and risks of traffic accidents. Speed limits must define safe speed, which maintains the function of the road, the ongoing traffic conditions and road design characteristics (ERSO, 2015). Otherwise, it may result in a mismatch between the driver's perception of the appropriate speed on a particular road section and the set speed limit. The perception of safe travelling speed is very important and depends on the road geometry and environment, the land use in the immediate vicinity of the road and weather conditions (Wilmot \& Khanal, 1999). Generally, drivers drive at higher speeds on wider roads, roads without curves, roads with good road conditions (Elliott et al., 2003; Martens et al., 1997) and in the presence of fewer buildings, trees and vegetation along the road (Elliott et al., 2003). A credible speed limit is defined as a speed limit that matches the image evoked by the road and traffic conditions (SWOV, 2012). It is important that the speed limit is neither too high nor too low given the road design speed, as its validity is then negated.

However, setting speed limits will not automatically lead to the compliance with the required speed. In all road categories, exceeding the speed limit is very common. It is generally found that $40-50 \%$ of drivers drive faster than the set speed limit (OECD / ECMT, 2006). In a survey conducted by BRAKE (2004), $68 \%$ of the drivers stated that they had exceeded the speed limit in the year before the survey, and $85 \%$ acknowledged that they sometimes did not respect the set speed limit. Drivers often cite exceeding speed limits as an activity which they participate in (LDfT, 2010).

One of the reasons why drivers exceed the set speed limits is the credibility of the set speed limit (Fildes and Lee, 1993; van Schagen et al., 2004). Goldenbeld \& van Schagen (2007) state that it can generally be assumed that drivers will drive in accordance with the set speed limit if they consider it reasonable or "credible". However, if the set speed limit is not in line with the limit that drivers consider appropriate given the relevant road characteristics, then the set speed limit could be ignored by the drivers. Goldenbeld \& van Schagen (2007) further state that if non-credible speed limits often occur in the system, the entire speed management system may be disputed. Gardner \& Rockwell (1983) found that drivers tend to rely more on their own estimates of appropriate speed than on the set speed limit. In addition to the problems of traffic flow efficiency, noncredible speed limits have a pronounced impact on traffic safety. Specifically, the high dispersion of speeds in the traffic flow leads to an increased risk of accidents. The greater the difference in vehicle speeds, the greater the number of traffic accidents (Aarts and Van Schagen, 2006; Montella et al., 2015) and the severity of the consequences of road accidents (Yu and Abdel-Aty, 2014a, 2014b). On rural roads, the risk of a traffic accident increases exponentially with the increase of free flow speed, i.e. illegal speeding increases the number of traffic accidents (Kloeden $e t$ al., 2001).

Also, previous research has shown that drivers whose speed deviates greatly from the established limit are more likely to be involved in traffic accidents (Solomon, 1964). Analyzing the relationship between vehicle speed and accident rate on US highways, 
Solomon (1964) concluded that vehicles travelling up to $10 \mathrm{~km} / \mathrm{h}$ faster than the speed limit had the lowest accident rate while vehicles travelling significantly slower or faster than the prescribed speed had a greater chance of participating in accidents. The presented results lead to the conclusion that a certain degree of adjusting of driving speeds with speed limits plays a very important role in achieving the maximization of road users' safety.

Considering the importance of speed in the functioning of the traffic system, the aim of this paper is to conduct an analysis of all relevant speeds within the zone of the automatic traffic counters (ATCs) as well as along the sections of two-lane rural valley roads, in order to recognize the factors that have an impact on speeds, identify the causes and consequences of possible traffic and safety issues, and finally provide certain conclusions, measures and recommendations. The paper focused on six sections on State Roads IB 22, IB 23 and IB 28. The analyzed sections are: Mataruška Banja - Ušće, Ušće - Bare, Čačak (Guča) - Pakovraće (Markovica), Pakovraće (Markovica) - Kratovska Stena, Mali Zvornik - Gračanica, and Gračanica - Ljubovija.

\section{Research Methodology}

The following Figure (Fig. 1) presents the algorithm of the research methodology:

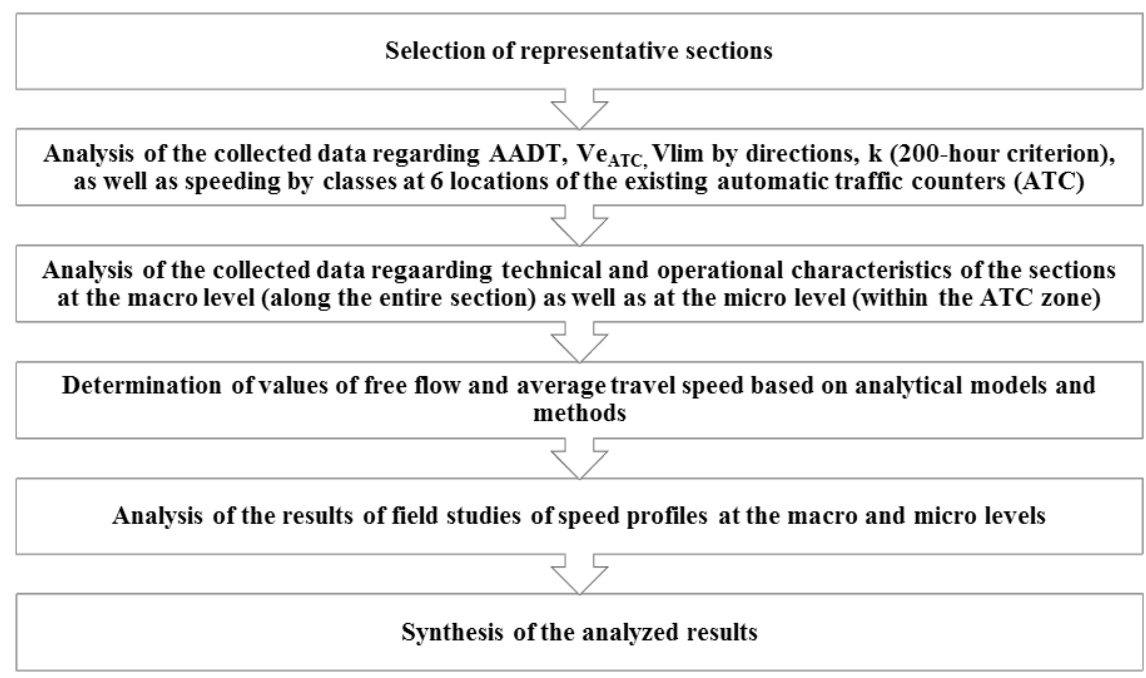

Fig. 1.

An Algorithm for Research Methodology

The aim of the research is to determine the trend of speed changes in space at the micro level ( $1000 \mathrm{~m}$ before and after the ATC) and the macro level (along the entire segment) on the sections of the two-lane valley roads. Also, in order to identify the factors that affect the traffic conditions, a complete speed analysis was performed along homogeneous segments (in the ATC zone).

The paper deals with six sections belonging to the state roads IB 22, IB 23 and IB 28 . In 
order to perform a detailed analysis of speeds along homogeneous segments of the section, it was necessary to collect data from the ATC regarding the annual average daily traffic (AADT), actual speeds $\left(\mathrm{Ve}_{\text {ATC }}\right)$, speed limits per direction, and design hourly volumes (200 ${ }^{\text {th }}$ highest hourly traffic volume). Then, an in-depth analysis of speeding by class was carried out at the 6 locations of the existing Automatic Traffic Counters (ATC), placed on the analyzed sections. The base year for the survey was 2016. Since the speed change per year is very low, it is relevant to analyze the last available year. Then, the technical and operational characteristics of the sections were determined (carriageway width, lane width, number of traffic lanes, shoulder width, minimum radius of horizontal curvature, maximum and average longitudinal profile) based on the current State Roads Database. Other influential parameters that were included in the calculation of operating speeds (the percentage of the allowed overtaking and number of access points) were determined by the empirical research in the field.

In the next step, the analysis of free flow speeds, which are related to the technical and operational characteristics of the carriageway and the characteristics of the traffic flow, was carried out on the basis of the Linear model developed at the Faculty of Transport and Traffic Engineering (Kuzović, 1994). Also, the same model was used to analyze the operating speed. Following the calculation of free flow and operating speeds, in order to obtain more realistic data, the calculation of the same speeds was made based on the HCM (2000) procedure, using the HCS software. In this procedure, the calculation of free flow and operating speeds is influenced not only by the technical and operational characteristics, traffic volume, traffic flow structure, time irregularity and peak hour factors, but also by access control (number of access points per $1 \mathrm{~km}$ of the section) and the percentage of no passing zone.

Finally, in order to obtain a clearer insight into the changes of speeds in space and time, speed measurements were performed in reallife conditions using an Android application along the six selected sections (macro level). The research was performed by the floating vehicle method (Kajalić et al., 2018). In other words, the vehicle of the observer was moving in the traffic flow, imitating the representative vehicle. With the aim of obtaining realistic data, special care was taken to include the recording vehicle in the traffic flow $\mathbf{3 0 0}$ meters before entering the recording area and thus reach an actual speed at the beginning of the zone. In order to provide a clearer insight into the situation, an analysis of ATC data was conducted prior to conducting the survey to determine the relevant days and hours for conducting the survey. Therefore, the survey was conducted during the representative days, hours or at the representative traffic loads, twice for each direction. Also, since the application is GPS based, the survey was conducted on sunny days, due to the fact that poor weather conditions can affect the operation and accuracy of the GPS system.

In the final step, after the data collection and analysis had been performed, a synthetic analysis of the data was conducted. On the basis of this analysis, the factors affecting speeds were identified, and the causes and consequences that had an impact on traffic efficiency and safety were underlined. 


\section{Research Results}

A thorough investigation of speeds at the micro level, i.e. along homogeneous segments of the sections ( $1000 \mathrm{~m}$ to the before and after of the ATC) as well as at the macro level (along the sections which are the subject of the analysis), resulted in the analysis and synthesis of the obtained results which are presented in this chapter.

\subsection{Results of the Micro Level Research}

In order to consider the effect of the speed limits on the actual speeds realized in the traffic flow, the free flow speeds obtained through the Linear procedure and the HCM (2000) procedure were compared with the actual speeds read from the ATCs (Fig. 2).

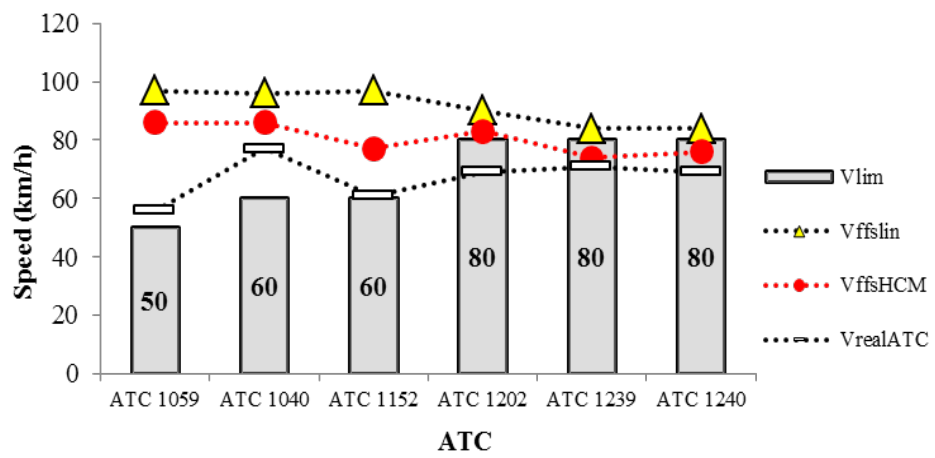

Fig. 2.

Relationship between Free Flow, Limited and Operating Speeds Read From ATCs

It can be noticed from that significant differences were obtained between the free flow speeds calculated using the two procedures. In addition to technical and operational characteristics, traffic volume, traffic flow structure, weather irregularity and peak hour factors, the HCM (2000) procedure also includes the influence of access control (the number of access points per 1 $\mathrm{km}$ of the section) and the percentage of no passing zone. Therefore, this procedure is considered more appropriate for application in local conditions. Figure 2 shows that in some homogeneous segments there is a large difference between free flow and limited speeds and this difference is up to $47 \mathrm{~km} / \mathrm{h}$ (Linear procedure) and $36 \mathrm{~km} / \mathrm{h}$
(HCM procedure). These results indicate that the speed limitation is rigorous and not harmonized with the technical and operational characteristics of the road. However, it increases traffic safety and is adapted to the characteristics of the environment (the local land use, adaptation of the road to the needs of settlements). Therefore, the defined speed limits, which are rigorous, have a significant negative impact on traffic flow efficiency, as it can be seen from Figure 2. Actual operating speeds are much lower than the calculated free flow speeds. On the other hand, on homogeneous segments with the general speed limit of $80 \mathrm{~km} / \mathrm{h}$, there is a greater concordance of all the speeds that are the subject of the analysis (Fig. 2). 


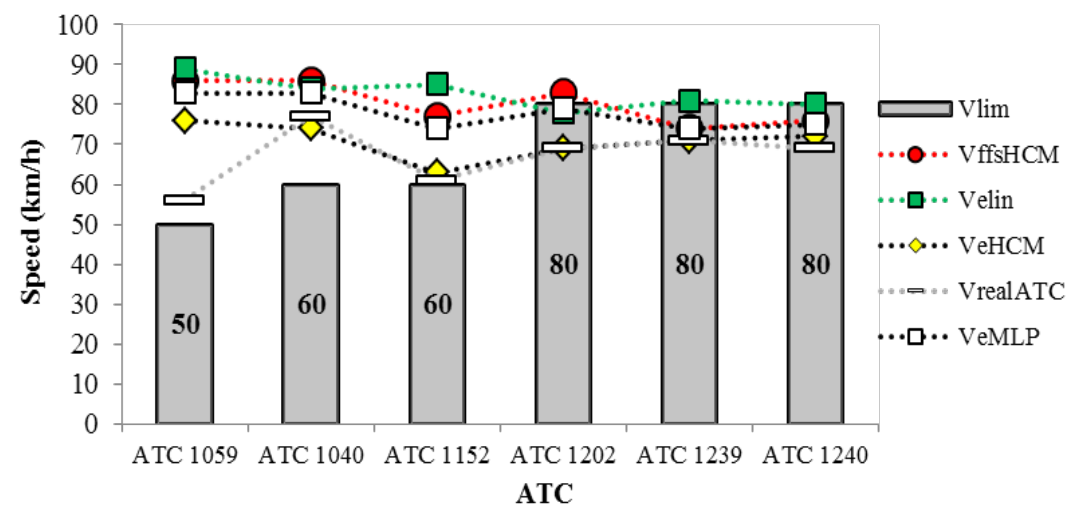

Fig. 3.

Relationship between Free Flow Speeds (Linear and HCM), Operating Speeds (Linear, HCM, Modified Linear Procedure - MLP and Actual Operating Speeds from ATCs) and Limited Speeds

Analyzing the data from Figure 3, it can be observed that along the first three homogeneous segments with the 50 and 60 $\mathrm{km} / \mathrm{h}$ limits, the Vffs value calculated by the HCM 2000 procedure is significantly higher than the speed limits. On the remaining three homogeneous segments with the general speed limit of $80 \mathrm{~km} / \mathrm{h}$, the obtained values of free-flow speeds are approximately similar to the limited speed. Also, Figure 3 shows that the actual speeds from the ATC are lower than the operating speeds obtained by the Linear Procedure, HCM (2000) and the modified linear procedure - "MLP", whereby the calculation of speeds by HCM (2000) gives the results which are the closest to the actual speeds. The summarized results for the analyzed six homogeneous segments indicate that along the first three homogeneous segments there is a problem with the credibility of the speed limits due to the significant difference between free flow and limited speeds and the fact that the actual speeds from the ATCs are lower than the operating speed values obtained by applying the model.
Namely, inappropriate speed limits at certain locations in the traffic system can results in the negative reaction of users. This reaction is reflected in the users' non-compliance with speed limits and therefore their non-compliance with other properly defined speed limits and other regulations. Since a credible speed limit is defined as a speed that is in line with the driver's perception of road and traffic conditions, the aforementioned sections raise the question of the credibility of the existing speed limits.

In order to further examine and verify the conditions in the traffic flow, i.e. to determine the main reasons for the imbalance between the analyzed speeds, a field survey was conducted. The conducted field study enabled the analysis of traffic flow speeds throughout the homogeneous ATC impact segment, as well as along the analyzed sections (space-mean speed). As an example of the above analysis, the results for some of the most characteristic segments are presented below (Fig. 4, 5 and 6). 


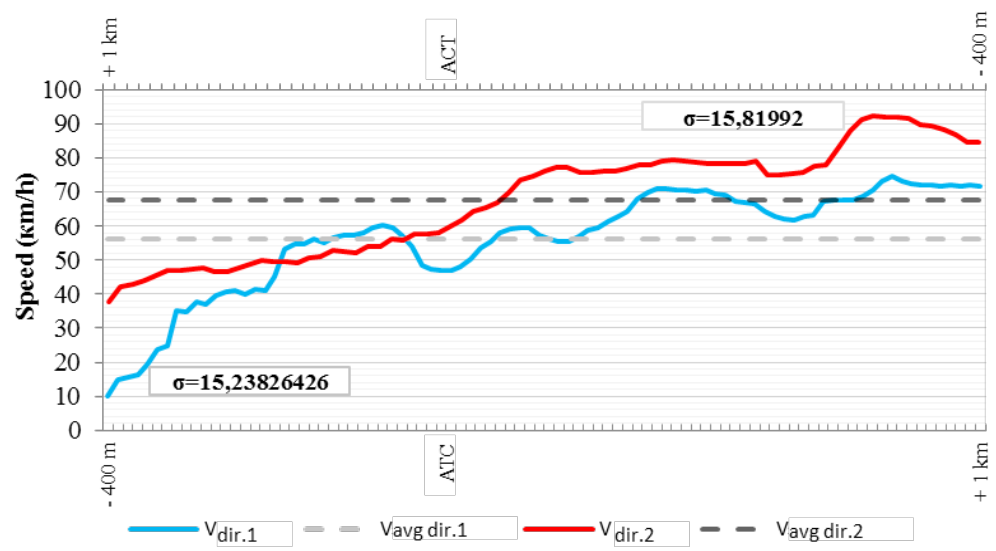

Fig. 4.

Speed Profile for the ATC Zone on the Section Mataruška Banja - Ušće (20.4.2019 at 12.49p.m. and 3.30p.m)

Figure 4 shows the results of the survey conducted on April 20, 2019. The graph shows that the speed profiles for both directions are almost identical, although a slightly lower speed value was recorded in the other direction. It can be seen that at the beginning of the section the speed is much lower than the limited speed of $50 \mathrm{~km} / \mathrm{h}$. The reason for this difference is the fact that at the beginning of the section the road intersects with the turn for Mataruška Banja, and due to the presence of this left turn, drivers are forced in some cases to reduce their speed to allow other drivers to safely engage in the traffic flow. Figure 4 also shows the tendency of speed increase, which is much higher than the limited speed at some locations. This tendency occurs because the road and traffic conditions in this part of the road network enable driving at higher speeds than the allowed ones. In fact, in this homogeneous segment there was a chaotic urbanization along the road, i.e. a settlement was formed without the access control and without a strategy for constructing a bypass, which led to problems related to traffic efficiency and safety. In order to ensure traffic safety, speed limitation has been a decades-long practice to solve this problem. However, since the road is designed for driving at the speed of $80 \mathrm{~km} / \mathrm{h}$ and the speed is limited to 50 $\mathrm{km} / \mathrm{h}$, this measure has led to the reduction of the operating speed in the traffic flow as well as a high percentage of non-compliance with the speed limits by drivers (70.22\% ). In the direction 1 , the obtained space-mean speed of $56 \mathrm{~km} / \mathrm{h}$ is identical to the obtained values of $\mathrm{Ve}_{\mathrm{ATC}}(56 \mathrm{~km} / \mathrm{h})$ and similar to the value for $\mathrm{Ve}_{\mathrm{HCM}}(62 \mathrm{~km} / \mathrm{h})$, while in the direction 2 a slightly higher value of spacemean speed $(67 \mathrm{~km} / \mathrm{h})$ was obtained. Due to the recorded high speed dispersion, high values of standard deviation were obtained for both directions (about 15). 
Fig. 5.

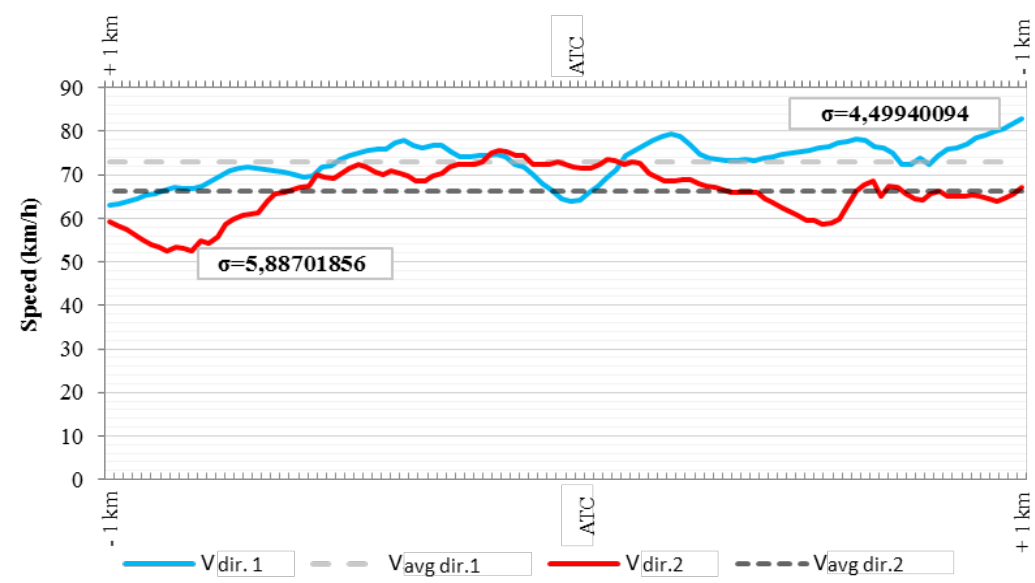

Speed Profile for the ATC Zone on the Ušće - Bare Section (10.11.2018 at 11.01a.m. and 11.26a.m)

Figure 5 shows the speed profile for the homogeneous segment in the ATC zone on the Ušće - Bare section. The results of the survey conducted on 10.11.2018 show that speeds in most places are significantly above the $60 \mathrm{~km} / \mathrm{h}$ speed limit, which is confirmed by the fact that $81.03 \%$ of drivers do not comply with the prescribed speed limit (2016). In both directions the obtained space-mean speed is above the speed limit. In the in direction 1 it is $73 \mathrm{~km} / \mathrm{h}$, while in the direction 2 it is slightly lower $(66 \mathrm{~km} / \mathrm{h})$. In the direction 1 , the obtained space-mean speed was nearly identical to Vactual ${ }_{\text {ATC }}$ $(76 \mathrm{~km} / \mathrm{h})$ and $\mathrm{Ve}_{\mathrm{HCM}}(74 \mathrm{~km} / \mathrm{h})$, while in the direction 2, the space-mean speed was slightly lower than Vactual ${ }_{\text {ATC }}(76 \mathrm{~km} / \mathrm{h})$ and $\mathrm{Ve}_{\mathrm{HCM}}(74 \mathrm{~km} / \mathrm{h})$. Figure 5 shows that the lower speed dispersion for both directions leads to the lower standard deviation.

Figure 6 presents the results of the survey conducted on April 4, 2019 under favourable weather and traffic conditions. Figure 6 shows that the speed profiles for both directions in the centre of the graph are almost identical, which is not the case for the speed profiles at the beginning and end of the homogeneous segment. There was a rapid increase in speed due to the overtaking of vehicles moving in front of the field survey vehicle. Looking at the graph, it can be seen that in most places, in both directions, the speed is greater than the allowed speed along the homogeneous segment. The calculated space-mean speed for both directions is almost identical; for the direction 1 it is 75 $\mathrm{km} / \mathrm{h}$, while for the direction 2 it is $74 \mathrm{~km} / \mathrm{h}$. The obtained results are in accordance with the data stating that in the ATC zone most drivers (55\%) do not respect the limited speed (2016). However, the calculated speed value obtained using the HCM procedure (63 $\mathrm{km} / \mathrm{h}$ ) and the obtained value of $61 \mathrm{~km} / \mathrm{h}$ for Vactual $_{\text {ATC }}$ are significantly lower than the obtained values for the space-mean speeds in both directions. Slightly higher values of standard deviation for both directions were obtained due to sudden oscillations in the overtaking phase (Fig. 6). 


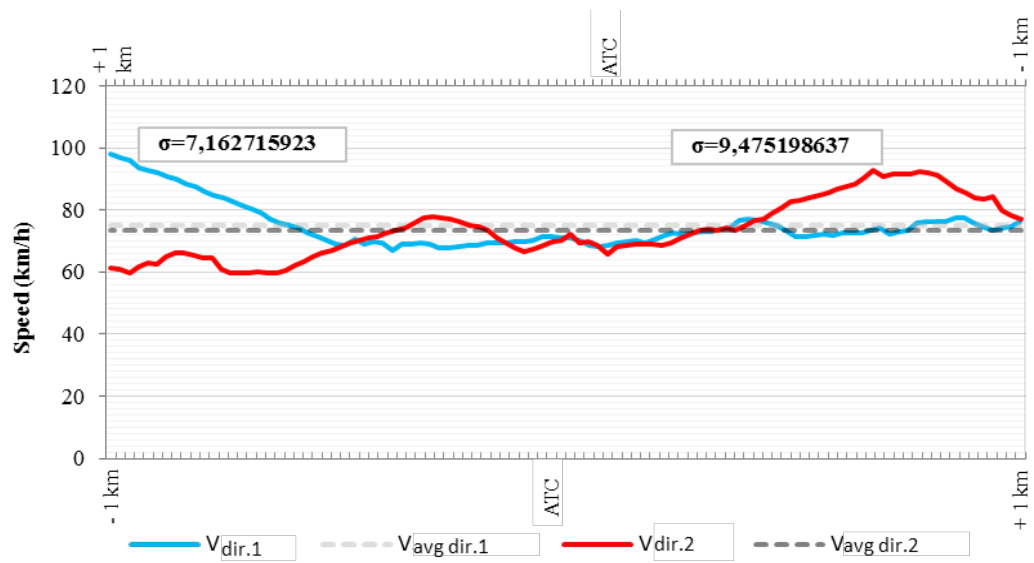

Fig. 6.

Speed Profile for ATC Zone on the Section Čačak (Guča) - Pakovraće (Markovica) (April 4, 2019 at 9. 16 a.m. \& 11.33 a.m)

Table 1 shows the overspeeding and the difference between the free flow speed calculated by the HCM (2000) procedure and the limited speed in the ATC zones (1 $\mathrm{km}$ before and after the ATC). From Table 1 it can be seen that on the first section in the zone of the automatic traffic counter (1059) the speed limit is $50 \mathrm{~km} / \mathrm{h}$ in both directions, and the calculation determined the difference between the free flow speed and the speed limit of $36 \mathrm{~km} / \mathrm{h}$. The obtained results indicate that the road and traffic conditions that prevail on the section allow the vehicles to move at higher speeds than allowed, which is confirmed by the fact that $70.29 \%$ of the drivers do not respect the prescribed speed limit, with the predominant driver class of those driving at speeds which are $10 \mathrm{~km} / \mathrm{h}$ higher than the speed limit (55.01\%). In the following analyzed section, within the zone of the automatic traffic counter 1040, the percentage of exceeding the speed limit of 60 $\mathrm{km} / \mathrm{h}(84.13 \%)$ was recorded, with a balanced redistribution of overspeeding by classes, and the difference between the free flow and limited speed of $26 \mathrm{~km} / \mathrm{h}$. The results of the analysis show that the limited speed is not in accordance with the technical and operational characteristics of the road, so drivers arbitrarily or under the influence of other participants in the traffic flow decide to drive at speeds higher than the limited ones. The ATC zone 1152, located on the section Čačak (Guča) - Pakovraće (Markovica), showed the difference between the free flow and limited speeds of $17 \mathrm{~km} / \mathrm{h}$. The table shows that out of the total percentage of the drivers who do not respect the speed limit (55\%), the highest number of drivers exceeds the speed limit by up to $10 \mathrm{~km} / \mathrm{h}(68.14 \%)$. The group of drivers exceeding the speed limit by up to $10 \mathrm{~km} / \mathrm{h}$ represents a group that can be influenced by certain coercive measures. These measures (primarily police controls) should be applied in order make this group start respecting the existing speed limits. On the section Pakovraće (Markovica) - Kratovska Stena, in the ATC zone 1202, the difference between the free flow and limited speeds is $3 \mathrm{~km} / \mathrm{h}$ and the percentage of drivers who do not respect the speed limit is $17.56 \%$, which is significantly lower than in 
the previous analyzed sections. In the zones of the last two analyzed ATCs, a negative difference was found between free and limited speeds, but despite this fact there are still drivers who do not respect the prescribed speed limit of $80 \mathrm{~km} / \mathrm{h}$. The largest number is those who drive at the speeds that are up to $10 \mathrm{~km} / \mathrm{h}$ higher than the limited speed. The obtained results show that a higher percentage of drivers do not respect the set speed limit on the sections where the difference between the free flow and limited speed is greater.

\section{Table 1}

Comparative Analysis of Exceeding the Speed Limit and the Difference between the Free Flow Speed Obtained by the HCM 2000 Procedure and the Speed Limit, in the ATC Zones

\begin{tabular}{|c|c|c|c|c|c|c|c|}
\hline \multirow[b]{2}{*}{ ID ATC } & \multirow{2}{*}{$\begin{array}{c}\mathbf{V}_{\lim } \\
(\mathbf{k m} / \mathbf{h})\end{array}$} & \multirow{2}{*}{$\begin{array}{c}\Delta\left(\mathbf{V f f s} \mathrm{HCM}_{\mathrm{HCM}}-\mathbf{V}_{\mathrm{lim}}\right) \\
(\mathbf{k m} / \mathbf{h})\end{array}$} & \multicolumn{5}{|c|}{ Exceeding (\%) } \\
\hline & & & Respects & Exceeds & $\begin{array}{c}0-10 \\
(\mathrm{~km} / \mathrm{h})\end{array}$ & $\begin{array}{c}10-20 \\
(\mathrm{~km} / \mathrm{h})\end{array}$ & $\begin{array}{c}>20 \\
(\mathrm{~km} / \mathrm{h})\end{array}$ \\
\hline 1059 (Konarevo) & 50 & 36 & 29,71 & 70,29 & 55,01 & 32,12 & 12,68 \\
\hline 1040 (Ušće) & 60 & 26 & 18,97 & 81,03 & 32,67 & 30,81 & 36.52 \\
\hline 1152 (Pridvorica) & 60 & 17 & 45,00 & 55,00 & 68,14 & 19,98 & 11,88 \\
\hline 1202 (Međuvršje) & 80 & 3 & 82,44 & 17,56 & 65,27 & 23,40 & 11,33 \\
\hline 1239 (Uzovnica) & 80 & -6 & 71,03 & 28,97 & 56,97 & 27,03 & 15,99 \\
\hline 1240 (Lonjin) & 80 & -4 & 77,50 & 22,50 & 60,31 & 25,64 & 14,05 \\
\hline
\end{tabular}

\subsection{Results of the Macro Level Research}

In order to determine space-mean speeds for the whole section and the percentage of the section length at which the drivers do not respect the speed limit, spatial analyses were conducted.
Spatial analyses were conducted for each section twice, for both directions, in order to obtain more reliable results. The results of the research on the section Mali Zvornik - Gračanica in both directions are shown as an example of the abovementioned analyses (Fig. 7 and 8).

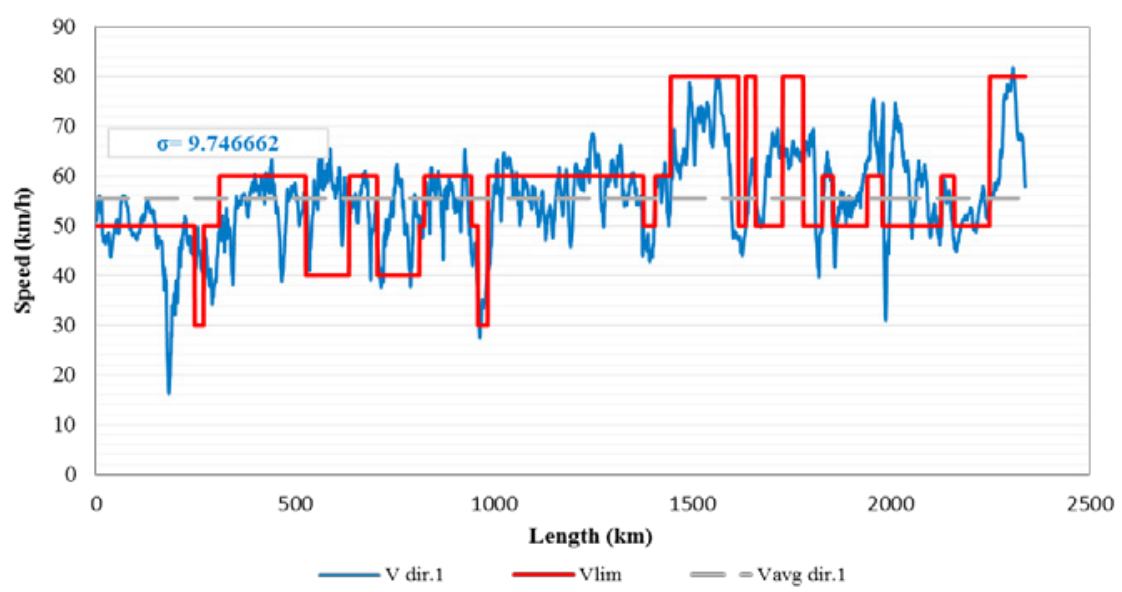

Fig. 7.

Speed Profile on the Section Mali Zvornik - Gračanica in Direction 1 (11/11/2018 at 10.52a.m) 
Figure 7 represents the speed profile for the direction 1 on the section Mali Zvornik - Gračanica. Figure 7 shows a significant oscillation of speeds, especially in the left side of the diagram. The reason for the dispersion of speeds is the passage of the road through the village of Mali Zvornik. Due to the presence of the school zone, pedestrians, bicycle traffic, as well as the lack of access control, it is necessary to reduce speed in some places. Given the significant oscillations in speed, a higher standard deviation value was obtained. The calculated space-mean speed is $55 \mathrm{~km} / \mathrm{h}$. Exceeding the speed limit in the direction 1 was recorded at $49.41 \%$ of the length of the Mali Zvornik - Gračanica section. Out of the total percentage of overspeeding, drivers most frequently exceeded the speed of 50 $\mathrm{km} / \mathrm{h}(17.42 \%)$. This is followed by the speed of $60 \mathrm{~km} / \mathrm{h}(17.42 \%), 40 \mathrm{~km} / \mathrm{h}(11.24 \%)$, while the lowest percentage of overspeeding $(2.25 \%)$ was recorded at the $80 \mathrm{~km} / \mathrm{h}$ limit.

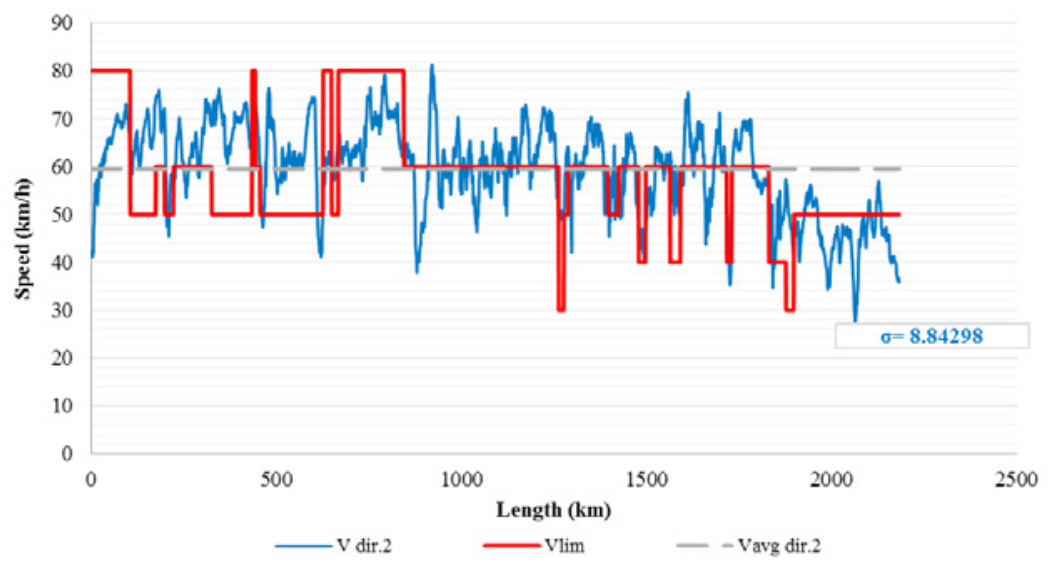

Fig. 8.

Speed Profile on the Section Mali Zvornik - Gračanica in Direction 2 (11/11/2018 at 12.02p.m)

Figure 8 is a graphical representation of the speed profile in the direction 2 on the Mali Zvornik - Gračanica section. As in the direction 1, Figure 8 shows the speed fluctuations resulting from the influence of the radius of the horizontal curvatures, the passage of the road through the settlement of Mali Zvornik, the absence of access control, as well as the impact of freight vehicles in the traffic flow. In view of this fact, the calculated standard deviation value is 8.84298 . The space-mean speed is $62 \mathrm{~km} / \mathrm{h}$, and overspeeding was observed at $69.11 \%$ of the length of the section. Out of the total percentage of overspeeding, the highest percentage of overspeeding $(60.24 \%)$ was recorded at the $60 \mathrm{~km} / \mathrm{h}$ limit and at the 50 $\mathrm{km} / \mathrm{h}$ limit (26.5\%), while much smaller percentage of overspeeding was recorded at the speed limits of 30, 40 and $80 \mathrm{~km} / \mathrm{h}$.

The data obtained per direction resulted in more comprehensive data regarding the spatial disregard of the speed limits along the observed sections. Tables 2, 3 and 4 show the summarized data on overspeeding on the 3 sections of valley routes where the survey was conducted. 


\section{Table 2}

Analysis of the Spatial Overspeeding on the Section Mali Zvornik - Gračanica (11.11.2018.)

\begin{tabular}{|c|c|c|c|c|c|c|c|}
\hline \multirow[b]{2}{*}{ Mali Zvornik - Gračanica } & \multicolumn{7}{|c|}{ Exceeding (\% of length) } \\
\hline & Respects & Exceeds & $\begin{array}{c}>\mathbf{8 0} \\
(\mathrm{km} / \mathrm{h})\end{array}$ & $\begin{array}{c}>60 \\
(\mathrm{~km} / \mathrm{h})\end{array}$ & $\begin{array}{c}>\mathbf{5 0} \\
(\mathrm{km} / \mathrm{h})\end{array}$ & $\begin{array}{c}>40 \\
(\mathrm{~km} / \mathrm{h})\end{array}$ & $\begin{array}{c}>30 \\
(\mathrm{~km} / \mathrm{h})\end{array}$ \\
\hline Direction 1 & 50,59 & 49,41 & 2,25 & 17,42 & 65,17 & 11,24 & 3,93 \\
\hline Direction 2 & 30,89 & 69,11 & 5,22 & 60,24 & 26,50 & 5,02 & 3,01 \\
\hline In total & 40,74 & 59,26 & 3,74 & 38,83 & 45,83 & 8,13 & 3,47 \\
\hline
\end{tabular}

\section{Table 3}

Analysis of the Spatial Overspeeding on the Section Mataruška Banja - Ušće (20.4.2019.)

\begin{tabular}{|c|c|c|c|c|c|c|c|}
\hline \multirow{2}{*}{ Mataruška Banja - Ušće } & \multicolumn{7}{|c|}{ Exceeding $(\%$ of length $)$} \\
\cline { 2 - 9 } & Respects & Exceeds & $\begin{array}{c}>\mathbf{8 0} \\
(\mathrm{km} / \mathrm{h})\end{array}$ & $\begin{array}{c}>\mathbf{6 0} \\
(\mathrm{km} / \mathrm{h})\end{array}$ & $\begin{array}{c}>\mathbf{5 0} \\
(\mathrm{km} / \mathrm{h})\end{array}$ & $\begin{array}{c}>\mathbf{4 0} \\
(\mathrm{km} / \mathrm{h})\end{array}$ & $\begin{array}{c}>30 \\
(\mathrm{~km} / \mathrm{h})\end{array}$ \\
\hline Direction 1 & 35,19 & $\mathbf{6 4 , 8 1}$ & 0 & 61,51 & 27,81 & 9,42 & 1,25 \\
\hline Direction 2 & 39,65 & $\mathbf{6 0 , 3 5}$ & 4,00 & 63,25 & 18,49 & 14,25 & 0 \\
\hline In total & $\mathbf{3 7 , 4 2}$ & $\mathbf{6 2 , 5 8}$ & $\mathbf{2 , 0 0}$ & $\mathbf{6 2 , 3 8}$ & $\mathbf{2 3 , 1 5}$ & $\mathbf{1 1 , 8 4}$ & $\mathbf{0 , 6 2}$ \\
\hline
\end{tabular}

\section{Table 4}

Analysis of the Spatial Overspeeding on the Section Čačak (Guča) - Pakovraće (Markovica) (20.4.2019.)

\begin{tabular}{|c|c|c|c|c|c|c|}
\hline \multirow{2}{*}{$\begin{array}{c}\text { Čačak (Guča) - Pakovraće } \\
(\text { Markovica) }\end{array}$} & \multicolumn{7}{|c|}{ Exceeding (\% of length) } \\
\cline { 2 - 8 } & Respects & Exceeds & $\begin{array}{c}\mathbf{> 8 0} \\
(\mathrm{km} / \mathrm{h})\end{array}$ & $\begin{array}{c}>\mathbf{7 0} \\
(\mathrm{km} / \mathrm{h})\end{array}$ & $\begin{array}{c}>\mathbf{6 0} \\
(\mathrm{km} / \mathrm{h})\end{array}$ & $\begin{array}{c}>\mathbf{5 0} \\
(\mathrm{km} / \mathrm{h})\end{array}$ \\
\hline Direction 1 & 82,41 & $\mathbf{1 7 , 5 9}$ & 4,27 & 57,26 & 14,53 & 23,93 \\
\hline Direction 2 & 73,68 & $\mathbf{2 6 , 3 2}$ & 0 & 21,71 & 69,71 & 8,57 \\
\hline In total & $\mathbf{7 8 , 0 0}$ & $\mathbf{2 2 , 0 0}$ & $\mathbf{2 , 1 6}$ & $\mathbf{3 9 , 4 7}$ & 42,12 & 16,25 \\
\hline
\end{tabular}

Tables 2, 3 and 4 show that the results obtained for the sections Mali Zvornik Gračanica and Mataruška Banja - Ušće indicate that the speed limits were noncredible, since there is a problem of overspeeding. On the other hand, the results obtained for the section Čačak (Guča) Pakovraće (Markovica) are satisfactory.

\section{Conclusion}

The conducted field research at the micro level (1000 $\mathrm{m}$ before and after the ATC) and the macro level (along the section) on the sections of the two-lane rural valley roads helped to determine the regularity of the change in space-mean speeds. Moreover, a complete analysis of the speeds along homogeneous segments (in the ATC zone) on the six observed sections made it possible to identify possible factors that have an impact on traffic conditions. The results obtained at the micro level (in the ATC zone) indicate that along homogeneous segments on the sections of Mataruška Banja - Ušće, Ušće - Bare and Čačak (Guča) Pakovraće (Markovica), the free flow speeds, operating speed according to the model, the obtained space-mean speeds as well as the actual average speed from the ATC are significantly higher than the speed limit. On these sections, within the ATC zone, speed limits are set in order to ensure traffic safety or adapt the road to the needs of the 
settlement (section Mataruška Banja - Ušće). However, this measure has a negative impact on traffic flow efficiency, and for this reason significantly lower speeds are realized than the road features allow. On all the observed homogeneous segments, the actual average speed in the traffic flow is much lower than the calculated free flow speed due to the lower speed limits. As a consequence of this difference, and the huge difference between the free flow and limited speeds, there is a high percentage overspeeding. Along the homogeneous segment on the section Mataruška Banja - Ušće, the difference of free flow and limited speeds is as high as $47 \mathrm{~km} / \mathrm{h}$ (Linear procedure) and the difference between free flow and actual operating speeds obtained from the ATC is $41 \mathrm{~km} / \mathrm{h}$ (Linear procedure). Similar results were obtained for the homogeneous segments on the Ušće - Bare and Čačak (Guča) - Pakovraće (Markovica) sections. On the remaining three homogeneous segments in the ATC zones on the sections of Pakovraće (Markovica) - Kratovska Stena, Mali Zvornik - Gračanica and Gračanica Ljubovija, with the general speed limit of $80 \mathrm{~km} / \mathrm{h}$, a significantly smaller difference was observed between the free flow speeds and actual operating speeds from the ATC, as well as between the free flow speeds and limited speeds. Also, the calculation of operating speed according to the model gave results that are almost identical to the data on operating speeds from the ATC. The obtained results are accompanied by the result that on the analyzed sections the limited speed is exceeded by a significantly smaller percentage of drivers, with the predominant group of drivers exceeding the speed limit by up to $10 \mathrm{~km} / \mathrm{h}$. The group of drivers who exceed the limit by up to 10 $\mathrm{km} / \mathrm{h}$ represents a group that can be adapted to the system, i.e. which can be influenced by certain measures (primarily police control, introduction of video surveillance).

Therefore, these measures need to be implemented in order to make this group of drivers respect the existing speed limits. The results of the micro-level speed analyses led to the following conclusions:

- When the speed limit is defined in order to ensure traffic safety or is adapted to the characteristics of the environment (the local land use, adjusting the road to the needs of settlements) but not to the technical and operational characteristics and characteristics of traffic flows, there is a large percentage of overspeeding and at the same time there is a high speed dispersion in the traffic flow;

- If value $\Delta$ (Vffs-Vlim) is higher, higher is the percentage of drivers who do not respect the speed limit, i.e. there is a lower percentage of drivers moving at the speeds that are lower than the speed limit.

The conducted field research along the observed segments enabled the determination of the space-mean speed in the traffic flow for the entire section, the percentage of the section length where drivers do not respect the speed limit and the determination of the behaviour of drivers at different speed limits along the section. The results of the spatial analysis showed that the highest percentage of overspeeding along the section was recorded on the routes with more frequent speed limitations of 30 , 40, 50 and $60 \mathrm{~km} / \mathrm{h}$ (Tables 2, 3, 4). Along all the analyzed sections that are extremely extra-urban, the general limit of $80 \mathrm{~km} / \mathrm{h}$ does not apply at most locations, although the sections have favourable road and traffic conditions that allow vehicles to travel at speeds faster that the speed limits. So far, 
speed limits have generally been defined in order to ensure traffic safety or adapt the road to the local land use. The results of the spatial analysis show that on the sections where the carriageway characteristics and the environment allow it, and where a large percentage of drivers exceed the speed limit, it is necessary to systematically address the problem of inadequate speed limits and improve the homogenization of speeds in the traffic flow. Defining and setting credible limits would primarily lead to a much smaller percentage of speed limit exceedance, decrease the speed dispersion in the traffic flow, and increase the capacity of the section. In addition to its positive effect on the traffic flow efficiency, this measure would also contribute to reducing the risk of traffic accidents, i.e. improving traffic safety.

\section{Acknowledgements}

This paper was supported by the project of the Ministry of Education, Science and Technological Development of the Republic of Serbia (No. 36027).

\section{References}

Aarts, L.; Van Schagen, I. 2006. Driving speed and the risk of road crashes: A review, Accident Analysis \& Prevention 38(2): 215-224.

BRAKE (Brake Road Safety Charity). 2004. The Green Flag Report on Safe Driving 2004 Part two: Speed. Available from internet: <https://www.brake.org.uk/ assets/docs/dl_reports/gf2_speed.pdf $>$.

Elliott, M.A.; McColl, V.A.; Kennedy, J.V. 2003. Road design measures to reduce drivers' speed via psychological processes: a literature review. TRL. $34 \mathrm{p}$.
ERSO (European Road Safety Observatory). 2015. Speed and Speed Management. Available from internet: <https://ec.europa.eu/transport/road safety/sites/roadsafety/files/ersosynthesis2015speedspeedmanagement 25 _en.pdf $>$.

Fildes, B.N.; Lee, S.J.; 1993. The speed review: road environment, behaviour, speed limits, enforcement and crashes. Report CR127. Federal Office of Road Safety, Department of Transport and Communications, Canberra, Australia.

Gardner, D.J.; Rockwell, T.H. 1983. Two views of motorist behavior in rural freeway construction and maintenance zones: the driver and the state highway patrolman, Human Factors 25(4): 415-424.

Goldenbeld, C.; van Schagen, I. 2007. The credibility of speed limits on $80 \mathrm{~km} / \mathrm{h}$ rural roads: The effects of road and person (ality) characteristics, Accident Analysis \& Prevention 39(6): 1121-1130.

HCM (Highway Capacity Manual). 2000. Highway Capacity Manual, Transportation Research Board, Washington D.C., Available from internet: <https:// sjnavarro.files.wordpress.com/2008/08/highway_ capacital_manual.pdf $>$.

Kajalić, J.; Čelar, N.; Stanković, S. 2018. Travel Time Estimation on Urban Street Segment, PrometTraffice Transportation 30(1): 115-120.

Kloeden, C.N.; Ponte, G.; McLean, J. 2001. Travelling speed and risk of crash involvement on rural roads. Australian Transport Safety Bureau.

Kuzović, Lj. 1994. Evaluation of the road network development management [In Serbian: Vrednovanje u upravljanju razvojem i eksploatacijom putne mreže]. University of Belgrade - Faculty of Transport and Traffic Engineering, Belgrade, Serbia, 56 p. 
LDfT (London Department for Transport). 2010. Understanding Public Attitudes to Road user Safety Literature Review: Final Report, Road Safety Research Report No. 112. Available from Internet: <https:// uwe-repository.worktribe.com/output/975717/ understanding-public-attitudes-to-road-user-safetyliterature-review-final-report-road-safety-researchreport-no-112>.

Martens, M.H.; Compte, S.; Kaptein, N.A. 1997. The effects of road design on speed behaviour: a literature review. Deliverable D1. TNO-report TM-97-B021. Soesterberg: TNO.

Montella, A.; Imbriani, L.L. 2015. Safety performance functions incorporating design consistency variables, Accident Analysis \& Prevention 74: 133-144.

OECD (Organisation for Economic Co-operation and Development) and ECMT (European Conference of Ministers of Transport). 2006. Speed management, Paris, France. Available from internet: <https://www. itf-oecd.org/sites/default/files/docs/06speed.pdf $>$.

Solomon, D.H. 1964. Accidents on Main Rural Highways: Related to Speed, Driver, and Vehicle. US Department of Transportation, Federal Highway Administration.
SWOV. 2012. Speed choice: the influence of man, vehicle, and road, Leidschendam, Netherlands. Available from internet: <https://www.swov.nl/sites/default/ files/publicaties/gearchiveerde-factsheet/uk/fs_speed choice_archived.pdf $>$.

Van Schagen, I.N.; Wegman, F.; Roszbach, R. 2004. Safe and credible speed limits: a strategic exploration. R2004-12. Leidschendam: SWOV Institute for Road Safety Research.

Wilmot, C.G.; Khanal, M. 1999. Effect of speed limits on speed and safety: a review, Transport Reviews 19(4): 315-329.

ty, M. 2014a. Analyzing crash injury severity for a mountainous freeway incorporating real-time traffic and weather data, Safety science 63: 50-56.

Yu, R.; Abdel-Aty, M. 2014b. An optimal variable speed limits system to ameliorate traffic safety risk, Transportation research part C: emerging technologies 46: 235-246. 